\title{
Understanding intrinsic challenges to STEM instructional practices for Chinese teachers based on their beliefs and knowledge base
}

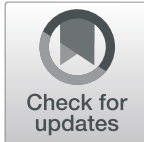

Yan Dong ${ }^{1}$, Jing Wang ${ }^{1}$, Yunying Yang ${ }^{2^{*}}$ (D) and Premnadh M. Kurup ${ }^{3}$

\begin{abstract}
Background: China has great student participation in STEM education. Chinese society has a progressive and positive attitude towards STEM as it is considered to provide more opportunities in life. Teachers play a vital role in the success of any STEM program in K-12 schools. However, teachers are facing instructional challenges because of the interdisciplinary nature of the STEM curriculum and the current typical school structure. The success of the STEM programs depends on teachers' beliefs and their knowledge in adapting to instructional implementation of STEM concepts.

Results: The data ( $n=216)$ was collected from STEM primary and secondary teachers from 25 provinces in mainland China. Exploratory factor analysis (EFA) was applied, and Pearson's correlation analysis was used to examine the correlation between Chinese STEM teachers' beliefs, knowledge, implementation, and the intrinsic challenges of STEM education; $t$ tests and analysis of variance (ANOVA) were performed to ascertain whether there were differences. The structural equation model (SEM) was applied to identify interrelationships. The results indicated that Chinese STEM teachers encounter higher-level intrinsic challenges to instructional implementations based on their beliefs and knowledge. Teachers who utilize their experience of teaching science as their main discipline and then attempt to integrate STEM using mathematics and engineering are likely to encounter higherlevel intrinsic challenges in implementation.

Conclusion: The intrinsic challenges perceived by Chinese teachers in the practice of STEM education can be predicted by their beliefs and knowledge base. Teachers who understand the nature and pedagogy of STEM education are more likely to encounter lower-level intrinsic challenges of STEM teaching, while teachers who utilize their main discipline when conducting integrated STEM learning activities through modeling based on science, technology, engineering, and mathematical problem situations are more likely to encounter higher-level intrinsic challenges. This study also reveals that there are some significant differences in the level of STEM teachers' beliefs, knowledge base, instructional practice, and their intrinsic challenges based on their teaching grade, seniority, and experience of STEM training and teaching.
\end{abstract}

Keywords: Intrinsic challenges, STEM education, Integrated STEM teaching and learning, Teachers' STEM beliefs and knowledge

\footnotetext{
* Correspondence: yunyingy@student.unimelb.edu.au

${ }^{2}$ Melbourne Graduate School of Education, The University of Melbourne,

Parkville, Melbourne, Victoria 3053, Australia

Full list of author information is available at the end of the article
}

Springer Open (c) The Author(s). 2020 Open Access This article is licensed under a Creative Commons Attribution 4.0 International License, which permits use, sharing, adaptation, distribution and reproduction in any medium or format, as long as you give appropriate credit to the original author(s) and the source, provide a link to the Creative Commons licence, and indicate if changes were made. The images or other third party material in this article are included in the article's Creative Commons licence, unless indicated otherwise in a credit line to the material. If material is not included in the article's Creative Commons licence and your intended use is not permitted by statutory regulation or exceeds the permitted use, you will need to obtain permission directly from the copyright holder. To view a copy of this licence, visit http://creativecommons.org/licenses/by/4.0/. 


\section{Introduction}

The growing role of STEM education does not happen in a vacuum. The STEM philosophy and its approaches in practice play a vital role in improving the economic and technological progress of a nation (Yildirim, 2016). However, there is a decline in the number of students opting for STEM subjects in many countries, due to a lack of public awareness and an undervaluing of STEM subjects (NRC, 2012; Tanenbaum, 2016). To respond to this challenge, STEM implementation should be a collective venture willingly undertaken, and effectively completed by teachers, students, and society (Freeman, 2015). Overall success in STEM education depends on a combination of curriculum focus, inclusion, the teacher's role, content structure, pedagogy, and accountability in teaching and learning (Osborne \& Dillon, 2008).

Teachers' beliefs, knowledge base, and understandings are the driving force for overcoming instructional challenges in STEM education (McMullin \& Reeve, 2014). It is of concern that the integrated nature of the STEM curriculum is a challenge, and typical school structures create a barrier for implementing some of the new practices which are necessary for STEM education. Most innovations tend to happen along with the traditional and routine business of teaching and learning, examinations, and reporting. Teachers also face various issues in developing STEM strategically in classrooms, such as adopting a pedagogical approach based on problem-based learning with an integrated approach connecting typical content from their disciplines (Asghar, Ellington, Rice, Johnson, \& Prime, 2012). STEM pedagogy also needs a fundamental shift in the classroom environment and teachers' attitudes, and integrating STEM subjects is always found by teachers to be a challenging process (Margot \& Kettler, 2019; Tao, 2019). This new pedagogy is in sharp contrast with traditional single-subject teaching.

Teachers' beliefs, knowledge, and current pedagogical practices could contribute to the intrinsic challenges, such as when they are striving to achieve student outcomes, are facing new pedagogical challenges, or are pursuing professional development (Ryder, 2015). This study was set in the context of K-12 education in China though, STEM reform efforts may shed light on other countries as different nations share some significant parallels and similarities, especially the implementation issues faced by teachers who are used to traditional in approaches (Ayres, 2016; Freeman, 2015; Holmlund, Lesseig, \& Slavit, 2018). China is moving very fast in the field of science and technology, and a large majority of the Chinese (more than 82\%) hold positive opinions regarding the awareness and valuing of STEM subjects as compared to most Western Countries (Gao, 2013).
It has drawn worldwide attention in that it has great student participation in STEM education, and there are greater opportunities for the next generation because of the promotion of STEM education (Marginson, Tytler, Freeman, \& Roberts, 2013).

\section{Literature review}

The Sociocultural Model of Embedded Belief Systems (Jones \& Carter, 2007) indicates that teachers' instructional practices are directly influenced by a series of belief systems, prior knowledge, epistemology, attitudes, knowledge, and skills. These factors are essentially interconnected, and teacher belief systems are the critical factor influencing practices. In the field of STEM education, STEM teachers' beliefs have been defined in many ways (Friedrichsen, Driel, \& Abell, 2011; Jones \& Leagon, 2014) and are classified into three major orientations. In the field of science, for instance, the first orientation points to the conceptions of science teaching and learning. Some researchers regard STEM teachers' beliefs as being about the roles of teachers and students, how students learn science, and how teachers teach science to make it more attractive and effective (Breslyn \& Mcginnis, 2012; Crippen, 2012; Kurup, Li, Powell, \& Brown, 2019; Luft \& Roehrig, 2007). The second orientation refers to the conceptions of the nature of science (Lederman, 1992; Sandoval, 2005), which can be generally divided into ontological beliefs and epistemological beliefs. The former is the beliefs about the reality or existence of scientific objects (Kwak, 2001), and the latter is about what knowledge is, and how it is produced, obtained, and justified (Hofer, 2001; Phillips, 1997; Schommer, 1994). The third orientation points to the conceptions of the goals or functions of science education (Olafson \& Schraw, 2006), including learning science or doing science (Hodson, 1992; Jones \& Carter, 2007), teaching science for students' intellectual development, individual self-realization, and the realization of social and economic benefits (Schulz, 2009).

This study focused on aspects covered in the third orientation, that is the degree to which STEM teachers believe that they can achieve the goals and functions of teaching and learning through the implementation of STEM courses, especially in designing coherent and integrated STEM education. This would depend on the overall factors arising from the relationships between teacher beliefs, their knowledge, and practices, along with the intrinsic challenges faced in integrating STEM disciplines. Studies have shown that teachers' existing knowledge base, beliefs, and instructional practices are based on an inquiry approach in STEM education; however, their content knowledge and pedagogical 
knowledge may not correlate (Yang, Kaiser, König, \& Blömeke, 2020).

The definition of STEM teachers' knowledge base also has a broad focus. Shulman $(1986,1987)$ summarized three forms of teachers' knowledge: propositional knowledge, case knowledge, and strategic knowledge. Propositional knowledge is stored in a statement of teaching and learning principles. Case knowledge is a kind of knowledge that describes specific teaching and learning events. Strategic knowledge is used to solve problems or conflicts encountered in teaching and learning activities. Pedagogical Content Knowledge (PCK) has been widely used in the literature about teachers' knowledge base in research on science and mathematics education (Kam, Chan, Yeh, \& Hsu, 2019). Technological Pedagogical Content Knowledge (TPACK) is an extension of PCK to the domain of technology, which includes teachers' knowledge of how to use emerging technologies to integrate specific subject or topic activities and how to teach specific topical content to promote student learning (Cox \& Graham, 2009; Koehler \& Mishra, 2005, 2009).

According to the TPACK framework theory, teachers' knowledge systems consist of seven components, including content knowledge, technology knowledge, pedagogy knowledge, pedagogical content knowledge, technological content knowledge, technological pedagogical knowledge, and technological pedagogical content knowledge (Koehler \& Mishra, 2005). Content knowledge is about the subject matter of teaching and learning. Technology knowledge is about modern technologies. Pedagogy knowledge is about the practices, strategies, processes and procedures, and methods of learning and teaching, or about the aims of instruction, assessment, and student learning. Pedagogical content knowledge is a kind of pedagogy knowledge focused on teaching a specific subject matter. Technological content knowledge is about how applications of technology transform the formulation and presentation of a specific subject matter. Technological pedagogical knowledge is about how technology applications support the realization of pedagogical goals. This study mainly adopted the TPACK framework to define STEM teachers' knowledge base and described it as all information related to STEM education held by STEM teachers (Wahono \& Chang, 2019a, 2019b).

The term "STEM teachers' instructional practices" always refers to the performance of STEM teachers in the classroom (Wahono \& Chang, 2019a, 2019b). Although there are no well-defined approaches for STEM implementation (English, 2016; Kelley \& Knowles, 2016; Nathan \& Pearson, 2014), some key features could be summarized to guide the design and implementation of STEM education. Moore et al. (2014) summarized six major ways in which teachers apply STEM education in classrooms through a review of the US state content standard documents on STEM education. They include mathematics and scientific content, adopting a studentcentered pedagogy, creating an attractive and motivating classroom context, arranging learning tasks about engineering design challenges, guiding students to learn from their mistakes, and emphasizing cooperative learning.

"Intrinsic challenges of STEM teachers" refers to a situation which presents difficulties for teachers in achieving goals and pursuing professional development (Schoepp, 2004). It is associated with teachers' personal competence and teaching practices (Akuma \& Callaghan, 2019), including pedagogical challenges, curriculum challenges, student concerns and challenges from assessment, and their time and knowledge (Margot \& Kettler, 2019). Shernoff, Sinha, Bressler, and Ginsburg (2017) summarized the challenges teachers face in achieving STEM, through semi-structured interviews with K-12 STEM teachers. They identified the following six key aspects:

- A lack of understanding of the interdisciplinary nature of STEM-based curricula, specifically not knowing how to effectively integrate STEM-related subject areas:

- A lack of understanding of content and standards in other subjects that they do not major in, especially not understanding what engineering education is;

- A lack of time, including the time for collaborative planning, integrating content from different disciplines, developing STEM curriculum activities with other fellow teachers, and implementing STEM teaching and learning activities;

- The influence of school organization and structure;

- The impact of traditional exams;

- Insufficient teaching resources and materials.

This study adopted the internal factors of all these issues concerned with the intrinsic challenges faced by STEM teachers in integrating subjects. That is, the core concepts of specific subjects and interdisciplinary concepts of STEM, teachers' pedagogical knowledge of implementing STEM in the classroom, and the interrelationships among the different disciplines of STEM.

\section{Conceptual framework}

STEM education deals with complex solutions which require a collective responsibility from everyone in society. STEM programs should provide for societal participation. This would support life-long participation in STEM learning, for example, in relation to the need for changes in practices to ensure future sustainability (Hoachlander \& Yanofsky, 2011). Effectively using a suite of the twentyfirst century skills such as adaptability, innovation, and 
complex communication to conceptualize and utilize information literacy by means of STEM education via science, mathematics, technology, and engineering practices needs an integrated approach and a strong knowledge base (Storksdieck, 2016). In this process, teachers are required to extend their knowledge of interdisciplinary inquiry procedures and connect these to classroom practices (Fensham, 2015, 2016). Interdisciplinary approaches support and provide scope for innovative STEM practices in the teaching and learning process as well as empower teachers' effective implementation of STEM (Kristin et al., 2017). For instance, interdisciplinary approaches to innovations (Johnson \& Brown, 2011) align with the Next-Generation Science Standards (NGSS Lead States, 2013) and the National Research Council's (National Research Council, 2013) focus on the integration of divergent thinking, which lead to a change in practices and scenarios in classrooms. Such approaches involve different ways of thinking, solving problems, and communicating.

Teachers' beliefs about the interdisciplinary nature STEM would likely be connecting teaching to daily life, improving students' skills for the twentyfirst century, and cultivating their talents for careers related to STEM (El-Deghaidy, Mansour, Alzaghibi, \& Alhammad, 2017). The beliefs of teachers are constituted by the clarity of the scientific discourse they have access to and their assessment of that scientific information and are connected to their knowledge regarding the wide range of challenges concerning STEM education (Schultz, 2001). The interpretation of scientific and technological issues associated with STEM not only requires a platform of scientific knowledge but also positively held beliefs about the intrinsic challenges and impacts on instructional capabilities (Thomm \& Bromme, 2012).
STEM teachers' challenges are associated with instructional materials and the implementation of teaching practices (Bybee, 2013). Wahono and Chang (2019a, $2019 \mathrm{~b})$ summarised the three main challenges teachers face in implementing STEM practices in their classrooms: (a) limited knowledge about STEM, (b) difficulties in connecting scientific topics and mathematics, and (c) the non-applicability of the STEM approach in some topics. The conceptual framework formulated in this research focuses on the instructional implementation of STEM, based on the beliefs and knowledge about classroom practices among Chinese teachers in relation to the intrinsic challenges they face (see Fig. 1).

\section{Purpose and research questions}

The purpose of this research was to investigate Chinese STEM teacher practitioners' intrinsic challenges to their STEM instructional practices based on their beliefs and knowledge base. Most of the time, teachers use their main discipline and integrate it with STEM practices to bridge across science, technology, engineering, and mathematics to help their students learn to solve social and technological challenges. More specifically, the following research question was formulated:

RQ: To what extent are the intrinsic challenges faced by Chinese STEM teachers' influenced by their beliefs, knowledge base, and instructional practices of STEM education?

This overall research question was broken into three sub-questions:

RQ 1 Can the intrinsic challenges perceived by Chinese teachers be predicted by their beliefs, knowledge base, and practice of STEM teaching?

RQ 2 What are the relationships among Chinese STEM teachers' beliefs, knowledge base, instructional

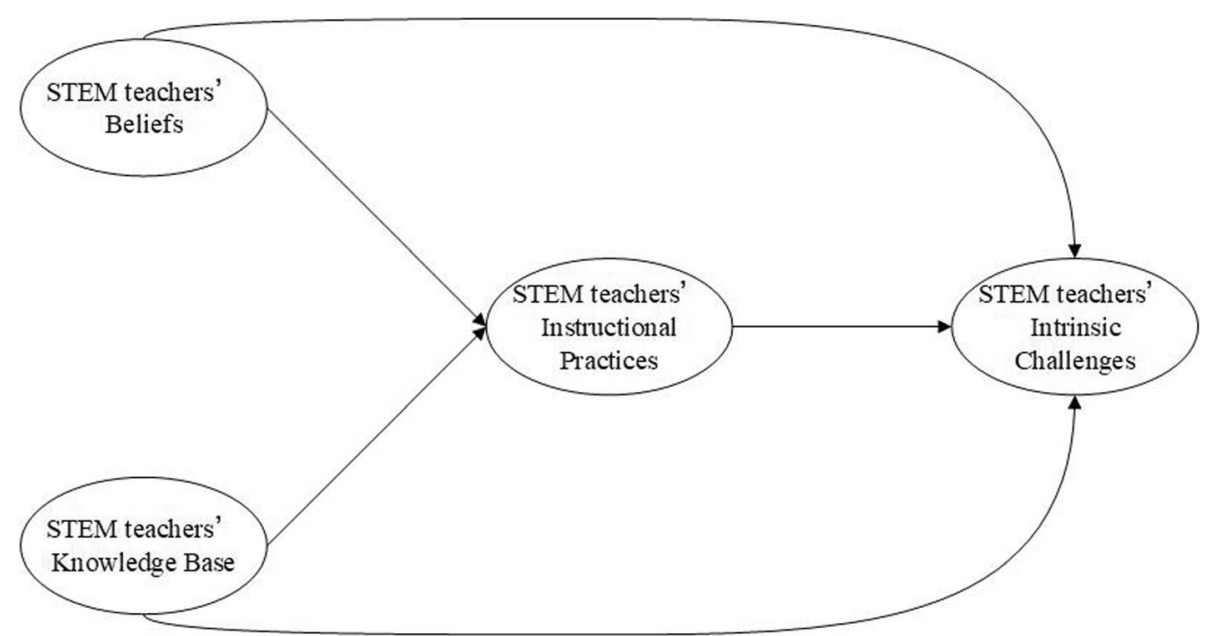

Fig. 1 Intrinsic challenges to STEM instructional practices perceived by teachers based on their beliefs and knowledge base 
practices, and their perceptions of the intrinsic challenges of STEM teaching?

RQ 3 How do STEM teachers' beliefs, knowledge base, instructional practices, and intrinsic challenges compare, based on teachers' teaching grade (i.e., the grade level that teachers teach at), seniority, and experience of STEM training and teaching?

\section{Methods}

\section{Background}

This research focused on obtaining information about the beliefs, knowledge base, instructional practices, and thus, the intrinsic challenges of STEM education faced by teachers who teach STEM-related subjects in China. The data, consisting of participants' demographics including gender, seniority, grade, and main subjects taught, and the experience of STEM training and teaching, was also collected. Presently, China lacks a systematic admittance system for the certification of new STEM teachers, and a training system is yet to be established. Mostly, STEM teachers are those subject teachers who have specialized in disciplinary major varying from mathematics, science-related subjects to information technology. They have been involved in STEM programs, activities, or researches such as teaching STEM lessons as extra-curriculum on-campus, running STEMrelated competition, or tutoring students in STEM relevant events. They may or may not have attended some STEM training programs which are specifically launched for preparing and training subject teachers on how to implement STEM education in schools. The survey has targeted these teachers and conducted through a Webbased questionnaire system in China. Participating in the survey was completely voluntary and anonymous. Finally, the methods were conducted to quantitatively examine the details of how STEM teachers' beliefs, knowledge base, and instructional practices affected the intrinsic challenges they face in STEM teaching.

\section{Instruments}

A survey instrument was used to measure a group of 216 Chinese STEM teachers through random sampling. The instrument consisted of four parts: STEM Teachers' Beliefs (STB), STEM Teachers' Knowledge (STK), STEM Teachers' Practices (STP), and STEM Teachers' Intrinsic Challenges (STC). The STB subscale was adapted by the authors, based on the descriptive framework of integrated STEM education (Nathan \& Pearson, 2014), and included 4 items. These 4 items described STEM teachers' expectations for the goals and functions of STEM education. An example of finding information about STEM teachers' beliefs was: "I believe that STEM education can stimulate students' interest in STEMrelated courses." Next, the subscales STK and STP were both adapted and translated from the Attitude, Knowledge, and Application (AKA) questionnaire (Wahono \& Chang, 2019a, 2019b), and included 5 and 4 items, respectively. Five items of the STK subscale were designed to investigate teachers' understanding of TPACK knowledge required by STEM education, with good reliability and validity ( $\alpha=0.90$, CVI $=0.83)$. An example of an item finding information regarding STEM teachers' knowledge was "I understand the core concepts of STEM-related disciplines." Four items of the STP subscale were used to measure how teachers implement STEM courses in the classroom, with good reliability and validity $(\alpha=0.86, \mathrm{CVI}=0.83)$. An example item was "I usually ask students to design tools or models in the STEM classroom." Finally, the STC subscale was also adapted by the authors, based on a qualitative study that examined the greatest challenges for STEM teachers in the USA to effectively implement STEM education (Shernoff et al., 2017) and included 4 items. These 4 items were utilized to explore the main challenges teachers faced in implementing STEM courses in the classroom. The sample item was "I don't know how to effectively integrate STEM-related subjects, which makes me find it very difficult to carry out STEM activities." All 17 items used a five-point Likert scale (1 strongly disagree to 5 strongly agree). In addition, there were also 7 items measuring respondents' demographic data.

\section{Participants}

A total of 216 STEM teachers from 25 provinces in mainland China took part in the survey. Between them, they taught STEM-related subjects in primary $(n=146$, $67.6 \%)$ and secondary schools $(n=70,32.4 \%)$, consisting 63 males (29.2\%) and 153 females (70.8\%). Their main teaching subjects were distributed across traditional disciplines, including 94 teachers majoring in science (43.5\%), 43 in technology (19.9\%), 15 in mathematics (6.9\%), and 64 in other subjects (29.6\%). The number of years of teaching of the respondents ranged from 1 to 38 , and 111 of them had fewer than 10 years (51.4\%), while 105 had more than 10 years of experience (48.6\%). With regard to the experience of STEM training, 104 of respondents $(48.1 \%)$ reported that they had "often" participated in training activities related to STEM education, and 112 (41.9\%) reported "rarely." With regard to the experience of teaching STEM courses, 74 (34.3\%) of respondents had "more" STEM teaching experience, and 142 (65.7\%) had "less" experience. All demographic data of the respondents is shown in Table 1.

\section{Data analysis}

Exploratory factor analysis (EFA) was conducted using SPSS software (version 20.0). EFA was applied to check whether the questionnaire used in this study was 
Table 1 Demographic statistics

\begin{tabular}{|c|c|c|c|}
\hline Variables & Category & Number & Percentage (\%) \\
\hline \multirow[t]{2}{*}{ Gender } & Male & 63 & 29.2 \\
\hline & Female & 153 & 70.8 \\
\hline \multirow[t]{2}{*}{ Educational background } & Bachelor & 162 & 75.0 \\
\hline & Master and others & 54 & 25.0 \\
\hline \multirow[t]{2}{*}{ Seniority } & $\geq 10$ years & 111 & 51.4 \\
\hline & $<10$ years & 105 & 48.6 \\
\hline \multirow[t]{2}{*}{ Grade } & Primary schools & 146 & 67.6 \\
\hline & Secondary schools & 70 & 32.4 \\
\hline \multirow[t]{4}{*}{ Area of specialization } & Science & 94 & 43.5 \\
\hline & Technology & 43 & 19.9 \\
\hline & Mathematics & 15 & 6.9 \\
\hline & Humanity and other subjects & 64 & 29.6 \\
\hline \multirow[t]{2}{*}{ STEM training experience } & Often & 104 & 48.1 \\
\hline & Rarely & 112 & 51.9 \\
\hline \multirow[t]{2}{*}{ STEM teaching experience } & More & 74 & 34.3 \\
\hline & Less & 142 & 65.7 \\
\hline
\end{tabular}

applicable to these STEM teachers in mainland China. Pearson's correlation analysis was used to examine the correlation between STB, STK, STP, and STC. $t$ tests were performed to ascertain whether there were differences in STB, STK, STP, and STC based on gender, seniority, grade, and main subjects taught, and experience of STEM training and teaching. Furthermore, because Pearson's correlation only describes linear dependencies of the factors, a structural equation model (SEM) was applied to construct the complex structural model of the relationship between STB, STK, STP, and STC, using SPSS Amos software (version 21.0).

\section{Results and discussion}

\section{Exploratory factor analysis}

In order to verify the structural validity of the questionnaire, exploratory factor analysis (EFA) was used on the sample data of the pilot study $(n=196)$ in order to identify and interpret the latent factors in teachers' beliefs, knowledge, implementation, and the intrinsic challenges of STEM teaching. We selected and retained the items with factor loadings higher than 0.60 for the formal study. As Schumacker and Lomax (2016) recommended, factor loading of all items used for CFA should be higher than 0.60; therefore, items with factor loadings less than 0.60 were omitted from the survey.

Before the EFA, the Kaiser-Meyer-Olkin (KMO) value was measured to test whether the sample size was statistically valid. The resulting KMO value was 0.89 , and Bartlett's test measures were all significant (chi-square $=$ 2247.57, $d f=136, p<0.001$ ), showing good feasibilities to perform EFA.
According to EFA, as shown in Table 2, a total of 17 items were extracted with factor loadings 0.6 or above, the total variance explained was $75.27 \%$, and the overall alpha was 0.83 . The four factors, which were labeled as STEM Teachers' Beliefs (STB), STEM Teachers'

Table 2 Pattern/structure coefficients for the scale $(n=196)$ Factor 1: STB Factor 2: STK Factor 3: STP Factor 4: STC

Factor 1: STEM Teachers' Beliefs (STB), $a=0.91$

STB10 0.77

STB11 0.87

STB12 0.88

STB13 0.87

Factor 2: STEM Teachers' Knowledge Base (STK), $a=0.91$

$\begin{array}{ll}\text { STK16 } & 0.61 \\ \text { STK18 } & 0.76 \\ \text { STK19 } & 0.87 \\ \text { STK20 } & 0.87 \\ \text { STK21 } & 0.89\end{array}$

Factor 3: STEM Teachers' Practices (STP), $a=0.90$

STP27 0.81

STP28 0.85

STP30 $\quad 0.84$

STP31 0.81

Factor 4: STEM Teachers' Intrinsic Challenge (STC), $a=0.84$

STC33 0.82

STC36 0.85

STC37 0.78

$\begin{array}{lr}\text { STC40 } & 0.80\end{array}$ 
Knowledge Base (STK), STEM Teachers' Instructional Practices (STP), and STEM Teachers' Intrinsic Challenges (STC), accounted for the $75.27 \%$ of the variance. The reliability (Cronbach's alpha) coefficients of these four factors were $0.91,0.91,0.90$, and 0.84 , respectively, and the overall reliability coefficient was 0.83 , suggesting that the reliability of the questionnaire was acceptable.

RQ1 Can the intrinsic challenges perceived by Chinese teachers be predicted by their beliefs, knowledge base, and practices of STEM teaching?

The results of Chinese STEM teachers' beliefs, knowledge base, instructional practices, and intrinsic challenges of STEM teaching are presented in Table 3. The four subscales' mean scores varied from 3.34 $(\mathrm{SD}=0.92)$ for STK to 4.40 (SD = 0.76) for STB. These results suggest that Chinese STEM teachers held a high level of positive beliefs about STEM teaching and also had a high level of performance in conducting of STEM courses. They strongly believed that STEM education could stimulate students' interest in learning, help them establish interdisciplinary connections, and enhance their abilities of learning and solving current social problems, thereby helping to cultivate practitioners in STEM-related fields. These teachers also had a high level of performance in the conducting of STEM courses. They usually used their technical, engineering, and mathematical backgrounds to explain scientific problems. They asked students to design tools and build models, and let them adopt mathematical thinking, engage in engineering \& design process planning, and use appropriate technology to support problem posing in the STEM classroom.

However, they may have had only a medium level of knowledge about STEM teaching. They did not have a good grasp of the disciplinary core ideas and crosscutting concepts in STEM education, their knowledge of STEM courses was not sufficient, and they did not understand well how STEM-related disciplines were connected. Moreover, these teachers still encountered intrinsic challenges at a moderately high level in the implementation of STEM courses. Many challenges, such as using technical tools, understanding engineering education, integrating STEM-related subjects, and coping

Table 3 Description statistics and reliability coefficient for each subscale $(n=216)$

\begin{tabular}{llll}
\hline & Mean & SD & Alpha \\
\hline STEM Teachers' Beliefs (STB) & 4.40 & 0.76 & 0.94 \\
STEM Teachers' Knowledge Base (STK) & 3.34 & 0.92 & 0.93 \\
STEM Teachers' Instructional Practices (STP) & 4.17 & 0.59 & 0.82 \\
STEM Teachers' Intrinsic Challenge (STC) & 3.64 & 0.82 & 0.82 \\
\hline
\end{tabular}

with traditional exams, made them find it very difficult to carry out STEM activities.

RQ2 What are the relationships among Chinese STEM teachers' beliefs, knowledge base, instructional practices, and their perceptions of the intrinsic challenges of STEM teaching?

The relationships among Chinese STEM teachers' beliefs, knowledge base, instructional practices, and intrinsic challenges of STEM teaching are shown in Table 4. The results suggest STB was significantly and positively correlated with STK $(r=0.24)$ and STP $(r=0.45)$, STK was significantly and positively correlated with STP $(r=$ $0.37)$ and negatively correlated with STC $(r=-0.28)$, and STP was significantly and negatively correlated with STC $(r=0.15)$.

Structural Model and Hypothesis Testing Structural equation modeling (SEM) and confirmatory factor analysis (CFA) were applied to verify the possible hypotheses mentioned above, and the results are shown in Fig. 2.

Path analysis results showed that STB had significant positive impacts on STP $(\beta=0.45, t=5.97, p<0.001)$; STK had significant positive impacts on STP $(\beta=0.33$, $t=4.53, p<0.001)$ and negative impacts on STC $(\beta=$ $-0.47, t=-5.61, p<0.001)$; and STP had significant positive impacts on STC $(\beta=0.39, t=3.83, p<0.001)$.

The CFA results revealed a moderate model fit (chisquare $=189.54, d f=114, p<0.001)$. The goodness-offit index is shown in Table 5, indicating that the model above constructed by four factors was reasonably acceptable.

RQ3 How do STEM teachers' beliefs, knowledge base, instructional practices, and intrinsic challenges compare, based on teachers' teaching grade, seniority, and experience of STEM training and teaching?

This research also revealed the differences in the level of STB, STK, STP, and STC, based on the demographic data of respondents. The results of the analysis showed that there were no significant differences between STB, STK, STP, and STC based on gender and educational background. In relation to the differences based on STEM teachers' main subjects taught, the results of the ANOVA analysis showed that there

Table 4 Correlation coefficients for variable pairs $(n=216)$

\begin{tabular}{llll}
\hline & 1 & 2 & 3 \\
\hline STEM Teachers' Beliefs (STB) & & & \\
2 STEM Teachers' Knowledge Base (STK) & $0.24^{* *}$ & & \\
3 STEM Teachers' Instructional Practices (STP) & $0.45^{* *}$ & $0.37^{* *}$ & \\
4 STEM Teachers' Intrinsic Challenges (STC) & 0.04 & $-0.28^{* *}$ & $0.15^{*}$ \\
\hline${ }^{*} p<0.05,{ }^{* *} p<0.01,{ }^{* *} p<0.001$ & & &
\end{tabular}




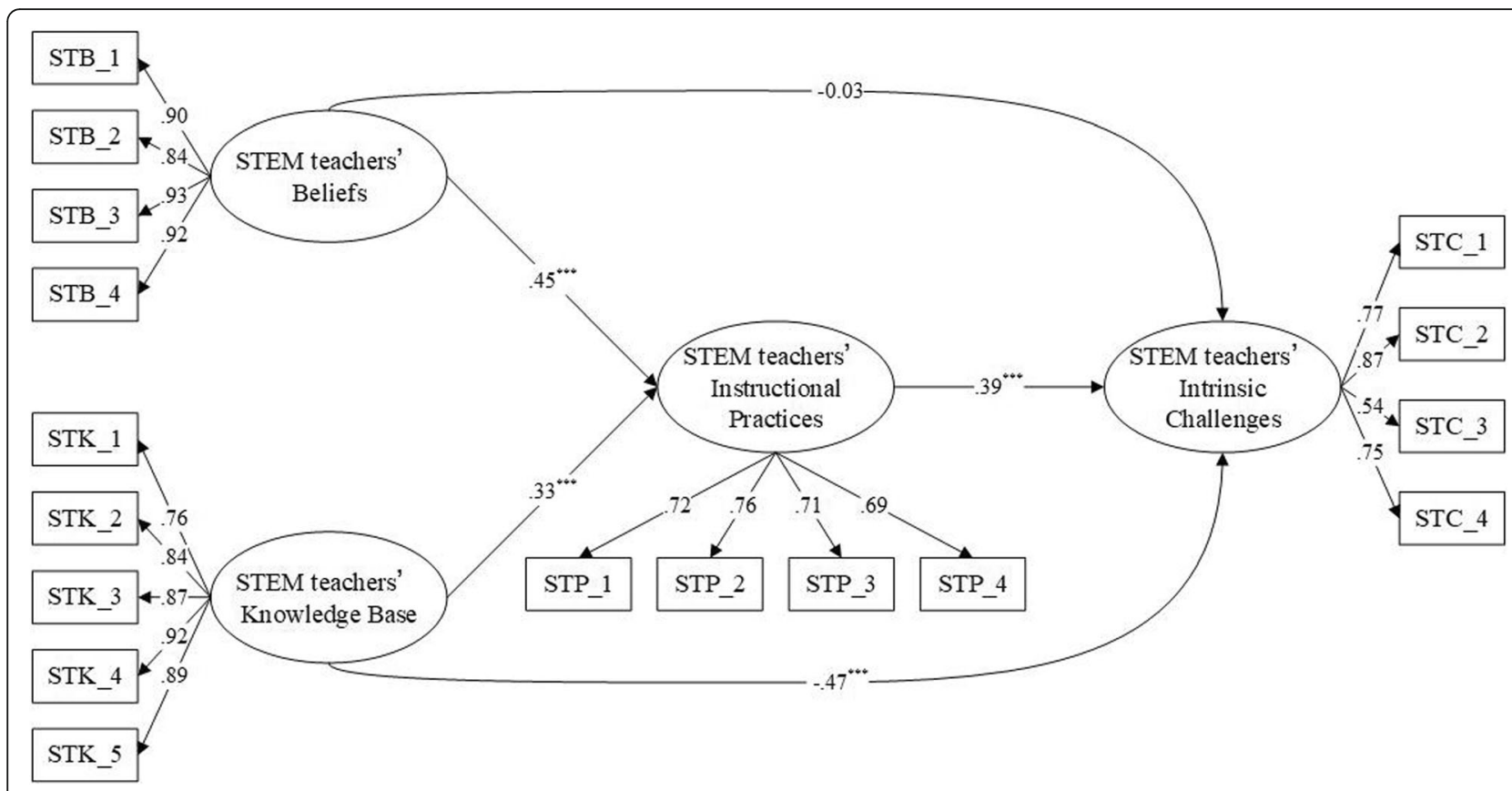

Fig. 2 Path analysis diagram and standardized path coefficients of the scale

was no significant difference among teachers majoring in different subjects.

However, there were some significant differences based on teaching grade, seniority, and experience of STEM training and teaching. The results of independent-sample $t$ test are shown in Table 6 .

In the STB and STP domains, there were significant differences based on teaching grade. STEM teachers who came from primary schools scored significantly higher than teachers who came from secondary schools on the STB and STP subscales. However, in the STK domain, there were significant differences based on teaching grade, seniority, and experience of STEM training and teaching. That is to say, on the STK subscale, primary STEM teachers scored significantly higher than secondary teachers, STEM teachers with more than 10 years of seniority scored significantly higher than teachers with less than 10 years of seniority, and STEM teachers with more experience of STEM training and teaching scored significantly higher than teachers with less experience. In the STC domain, there were significant differences based on seniority and experience of STEM training and teaching. In detail, on the STC subscale STEM teachers working more than 10 years scored significantly higher than those working fewer than 10 years, while STEM teachers with more experience of STEM training and teaching scored significantly lower than teachers with less experience.

In order to explore the difference of STEM teachers' training experience on the structural model of the four factors above, the research data was divided into two parts, according to the experience of training. The results of modeling the two sets of data by SEM are presented in Fig. 3.

For a set of data that marked the STEM training experience as "rarely" $(n=112)$, the model structure was consistent with that constructed in Fig. 2 using all the data $(n=216)$. STB had significant positive impacts on STP $(\beta=0.46, t=4.12, p<0.001)$; STK had significant positive impacts on STP $(\beta=0.35, t=3.30, p<0.01)$ and negative impacts on STC $(\beta=-0.42, t=-3.60, p<$ $0.001)$; and STP had significant positive impacts on STC $(\beta=0.46, t=3.00, p<0.01)$. However, the model

Table 5 Goodness-of-fit index of the structural equation model $(n=216)$

\begin{tabular}{lllllllll}
\hline & $X^{2} / \boldsymbol{d f}$ & GFI & NFI & RFI & IFI & CFI & RMR & RMSEA \\
\hline \multirow{2}{*}{ Criteria } & 1.66 & 0.91 & 0.93 & 0.91 & 0.97 & 0.97 & 0.07 & 0.06 \\
\hline
\end{tabular}


Table 6 Comparison of STB, STK, STP, and STC based on teachers' teaching grade, seniority, and the experience STEM training and teaching $(n=216)$

\begin{tabular}{|c|c|c|c|c|c|c|c|c|}
\hline & Teaching grade & & & & Seniority & & & \\
\hline & $\begin{array}{l}\text { Primary school (mean } \pm \text { SD) } \\
n=146\end{array}$ & $\begin{array}{l}\text { Secondary school (mean } \pm \\
\text { SD) } n=70\end{array}$ & $t$ & $p$ & $\begin{array}{l}<10 \text { years }(\text { mean } \pm S D) \\
n=111\end{array}$ & $\begin{array}{l}\geq 10 \text { years }(\text { mean } \pm S D) \\
n=105\end{array}$ & $t$ & $p$ \\
\hline STB & $4.47 \pm 0.74$ & $3.51 \pm 0.82$ & 2.07 & $0.04^{*}$ & $4.43 \pm 0.70$ & $4.36 \pm 0.82$ & 0.73 & 0.47 \\
\hline STK & $3.51 \pm 0.82$ & $2.98 \pm 1.03$ & 3.76 & $0.00^{* * *}$ & $3.10 \pm 0.94$ & $3.58 \pm 0.84$ & - & $0.00^{* * * *}$ \\
\hline STP & $4.27 \pm 0.55$ & $3.96 \pm 0.62$ & 3.75 & $0.00^{* * *}$ & $4.20 \pm 0.56$ & $4.14 \pm 0.62$ & 0.72 & 0.48 \\
\hline \multirow[t]{3}{*}{ STC } & $3.63 \pm 0.83$ & $3.67 \pm 0.82$ & $\overline{0}-\overline{34}$ & 0.73 & $3.77 \pm 0.82$ & $3.51 \pm 0.81$ & 2.27 & $0.03^{*}$ \\
\hline & Training experience & & & & Teaching experience & & & \\
\hline & $\begin{array}{l}\text { often } \\
\text { (Mean } \pm \text { SD), } \\
n=104\end{array}$ & $\begin{array}{l}\text { rarely } \\
(\text { Mean } \pm S D) \\
n=112\end{array}$ & $t$ & $p$ & $\begin{array}{l}\text { more } \\
(\text { Mean } \pm S D) \\
n=74\end{array}$ & $\begin{array}{l}\text { less } \\
\text { (Mean } \pm \text { SD), } \\
n=142\end{array}$ & $\mathrm{t}$ & $p$ \\
\hline STB & $4.49 \pm 0.78$ & $4.31 \pm 0.73$ & 1.68 & 0.09 & $4.53 \pm 0.66$ & $4.33 \pm 0.80$ & 1.89 & 0.06 \\
\hline STK & $3.65 \pm 0.73$ & $3.04 \pm 0.99$ & 5.12 & $0.00^{* * *}$ & $3.86 \pm 0.68$ & $3.06 \pm 0.92$ & 7.30 & $0.00^{* * *}$ \\
\hline STP & $4.17 \pm 0.61$ & $4.17 \pm 0.57$ & -0.04 & 0.97 & $4.21 \pm 0.66$ & $4.15 \pm 0.56$ & 0.66 & 0.51 \\
\hline STC & $3.43 \pm 0.78$ & $3.84 \pm 0.82$ & -3.82 & $0.00^{* * *}$ & $3.27 \pm 0.78$ & $3.84 \pm 0.78$ & -5.13 & $0.00^{* * *}$ \\
\hline
\end{tabular}

${ }^{*} p<0.05,{ }^{* *} p<0.01,{ }^{* * *} p<0.001$

structure was different for the set of data that marked the STEM training experience as "often" $(n=104)$. STB had significant positive impacts on STP $(\beta=0.46, t=$ $4.62, p<0.001)$; STK had significant positive impacts on STP $(\beta=0.37, t=3.71, p<0.001)$ and negative impacts on STC $(\beta=-0.37, t=-2.92, p<0.05)$; while STP had no significant impacts on STC.

\section{Major findings of this study}

Chinese teachers encounter high-level intrinsic challenges in implementing STEM programs. The major issues would appear to be the lack of knowledge of how to effectively integrate STEM-related disciplines and not being proficient with the technical tools required for STEM teaching and learning. The major weakness would appear to be the lack of understanding of engineering education. For Chinese teachers who frequently participate in professional development training activities, knowledge may be a key factor negatively affecting intrinsic challenges of STEM teaching; however, for teachers who rarely participate in them, practice may be a key factor positively affecting intrinsic challenges of STEM teaching. All these facts contributed to the main aspects of teachers' intrinsic challenges.

The intrinsic challenges perceived by Chinese teachers can be predicted by their knowledge base and beliefs, which are mediated by their STEM instructional practices. The following are the major aspects revealed, based on the analysis, including their interrelationships:

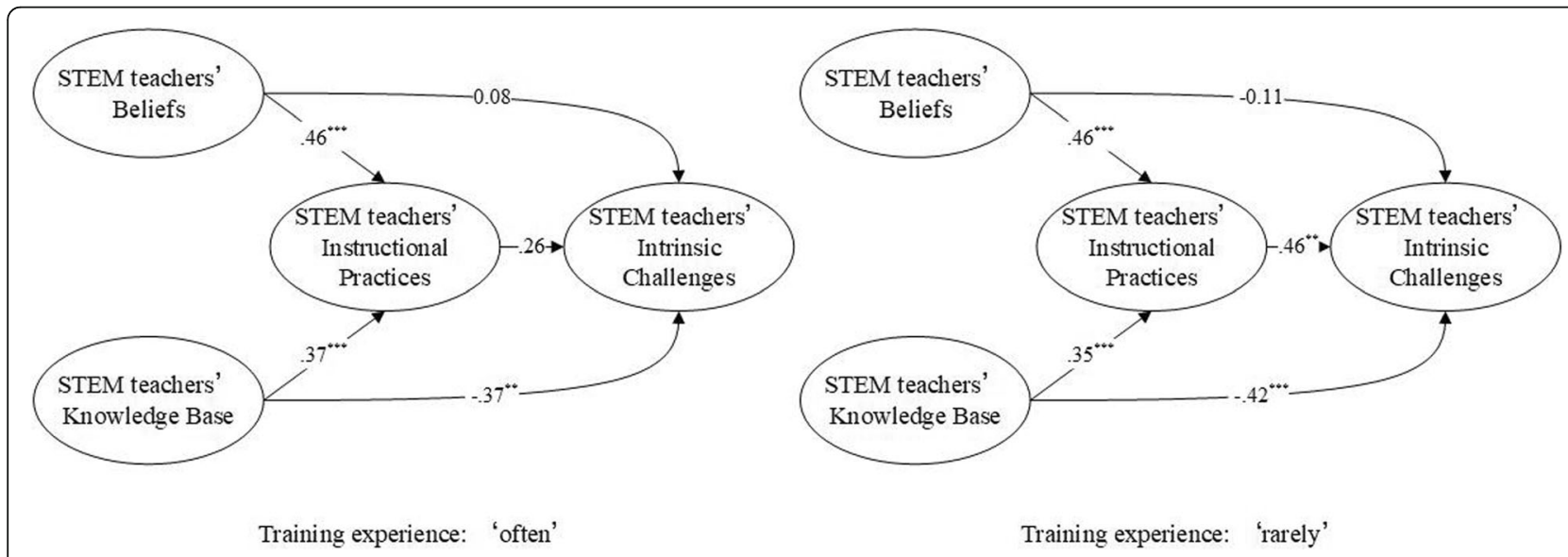

Fig. 3 The structural model with standardized coefficients based on the experience of STEM training 
- The intrinsic challenges perceived by Chinese teachers can be predicted directly by their knowledge and STEM instructional practices.

- A teacher who understands the nature, key features, and pedagogy of STEM education is more likely to encounter lower-level intrinsic challenges of STEM teaching; while a teacher who utilizes their main discipline and conducts STEM teaching activities through modeling based on technology, engineering, and mathematical problem situations is more likely to encounter higher-level intrinsic challenges.

- The beliefs held by Chinese teachers can predict their STEM instructional practices. In other words, a Chinese teacher who believes that STEM education is conducive to stimulating students' interest in learning, helping students to build bridges across different disciplines, and improving students' ability to respond to and solve current social problems, thereby cultivating practitioners in STEM-related industry fields, tends to enact STEM instructional practices that align with its interdisciplinary nature.

- For Chinese teachers who frequently participate in STEM training activities, knowledge may be a key factor negatively affecting (i.e., reducing) the intrinsic challenges of STEM teaching; however, for teachers who rarely participate in teacher training for STEM education, a practice may be a key positive factor (i.e., increasing the intrinsic challenges of STEM teaching).

\section{Limitations of this study}

This research focused on the beliefs, knowledge base, instructional practices, and intrinsic challenges of STEM teachers who taught STEM related subjects in China. The survey was conducted through a Webbased questionnaire system in China and was a quantitative analysis of how STEM teachers' beliefs, knowledge base, and instructional practices affected the perceived intrinsic challenges of STEM teaching. We have taken extreme care in the analysis of the data, using appropriate statistical techniques. The reality is that this is a sample of 216 teachers from 25 provinces of mainland China; extreme care should be taken in making broader generalizations based on this study.

Regarding the sample size, there is no consensus in the literature as to what would be an appropriate sample size for using SEM. Some evidence exists that simple SEM models could be meaningfully tested even if the sample size is quite small (Hoyle \& Kenny, 1999; Marsh \& Hau, 1999), but usually, $n=100-250$ is considered the minimum sample size for conducting SEM (Ding et al., 1995; Tabachnick \& Fidell, 2001), and for this study, with a sample of 216 , it is appropriate to use the SEM model.

\section{Conclusions}

The main findings of this study indicate that the intrinsic challenges perceived by Chinese teachers can be predicted by their knowledge base and beliefs which are mediated by their STEM instructional practices. A teacher who understands the nature, key features, and pedagogy of STEM education is more likely to encounter lower-level intrinsic challenges of STEM teaching compared to a teacher who utilizes their main discipline. There is a strong relationship shown between beliefs with knowledge and practices in the analysis, but a direct relationship between beliefs and perceived intrinsic challenges seems to be not as strong. This is natural as teachers' beliefs and knowledge influence how they teach STEM (Nadelson et al., 2013), but the reality of integrating the STEM curriculum seems to present a challenge to them (Hofer \& Grandgenett, 2012). The demands of a twentyfirst century education include challenges to existing practices and need a shift across all educational levels in integrating STEM disciplines (NRC, 2012). Teachers' beliefs and worldviews have a great influence on instructional practices in which they engage (Davis, 2003); in this study is evident that beliefs influence STEM instructional practices very strongly. There is a gap between beliefs and the intrinsic challenges teachers face, and to bridge this gap, there is a need for innovative practices in teacher preparation and teacher professional development (Barak, 2015; Kurup et al., 2019). Professional development has the protentional in different dimensions for providing teachers with the ability to deal with an integrated STEM approach and to improve their knowledge and pedagogical practices (Heck, Plumley, Stylianou, Smith, \& Moffett, 2019).

The findings of this study also suggest a possible relationship between the level of intrinsic challenges perceived by STEM teachers and their experience of STEM training. Teachers need support in STEM teaching and learning with the integration of STEM disciplines and appropriate resources for such pedagogical approaches (Estapa \& Tank, 2017). Professional development should provide support to teachers' dynamics in shifting to innovative pedagogical practices and integrating the different disciplines effectively (Du et al., 2019). Professional development for teachers can often successfully support self-efficacy and reduce challenges associated with STEM practices (Seals, Mehta, Berzina-Pitcher, \& Graves-Wolf, 2017). The complexities associated with the professional development of teachers to 
achieve the goal of an ideal STEM focus require innovations and informed decision-making (Fensham, 2016). Overall, this study revealed the current status of issues connected with Chinese STEM teachers' integrating STEM disciplines based on their current practices and the real need for further professional development. Further research is needed to investigate whether professional development training can reduce the level of intrinsic challenges perceived by STEM teachers, and whether STEM teachers who have a low level of knowledge base for teaching STEM can be supported by professional development training: If so, what kind of and content of professional development they need.

\section{Abbreviations}

STB: STEM Teachers' Beliefs; STK: STEM Teachers' Knowledge Base; STP: STEM Teachers' Instructional Practices; STC: STEM Teachers' Intrinsic Challenges

\section{Acknowledgements}

Not applicable.

\section{Authors' contributions}

This research is conducted by a team of researchers. Yan Dong and Jing Wang conducted the investigation and looked at the analysis of data and results. Yunying Yang and Premnadh $\mathrm{M}$. Kurup constructed the conceptual framework, reviewed the paper, and modified the draft. The authors read and approved the final manuscript.

\section{Funding}

This research was funded by the International Centre for Educational Research, Faculty of Education, Beijing Normal University, China, grant number [ICER201902].

\section{Availability of data and materials}

The datasets used and analyzed during the current study are available from the corresponding author on reasonable request. Please contact the author for data requests.

\section{Competing interests}

Authors declare that "There is no conflict of interest in this article from any of the authors".

\section{Author details}

${ }^{1}$ Faculty of Education, Beijing Normal University, Beijing, China. ${ }^{2}$ Melbourne Graduate School of Education, The University of Melbourne, Parkville, Melbourne, Victoria 3053, Australia. ${ }^{3}$ School of Education, La Trobe University, Melbourne, Australia.

Received: 11 February 2020 Accepted: 3 August 2020

Published online: 10 September 2020

\section{References}

Akuma, F. V., \& Callaghan, R. (2019). A systematic review characterizing and clarifying intrinsic teaching challenges linked to inquiry-based practical work. Journal of Research in Science Teaching, 56(5), 619-648.

Asghar, A., Ellington, R., Rice, E., Johnson, F., \& Prime, G. M. (2012). Supporting STEM education in secondary science contexts. Interdisciplinary Journal of Problem-Based Learning, 6(2), 4. https://docs.lib.purdue.edu/ijpbl/vol6/iss2/4/.

Ayres, D. C. (2016). A collaborative integrated STEM teaching: Examination of a science and math teacher collaboration on an integrated STEM unit (ProQuest No. 10146270) [Master's thesis, Purdue University]. ProQuest Dissertations and Theses Global.

Barak, M. E. M. (2015). Inclusion is the key to diversity management, but what is inclusion?. Human Service Organizations: Management, Leadership \& Governance, 39(2), 83-88. https://doi.org/10.1080/23303131.2015.1035599
Breslyn, W., \& McGinnis, J. R. (2012). A comparison of exemplary biology, chemistry, earth science, and physics teachers' conceptions and enactment of inquiry. Science Education, 96(1), 48-77.

Bybee, R. W. (2013). The case for STEM education: challenges and opportunities. NSTA press.

Cox, S., \& Graham, C. R. (2009). Using an elaborated model of the TPACK framework to analyze and depict teacher knowledge. TechTrends, 53(5), 60-69.

Crippen, K. J. (2012). Argument as professional development: impacting teacher knowledge and beliefs about science. Journal of Science Teacher Education, 23(8), 847-866.

Davis, A. (2003). Teachers' and students' beliefs regarding aspects of language learning, Evaluation and Research in Education, 17(4), 207-222. https://doi.org/ 10.1080/09500790308668303

Ding, L., Velicer, W., \& Harlow, L. (1995). Effects of estimation methods, number of indicators per factor, and improper solutions on structural equation modeling fit indices. Structural Equation Modeling: A Multidisciplinary Journal, 2(2), 119-143.

Du, W., Liu, D., Johnson, C. C., Sondergeld, T. A., Bolshakova, V. L. J., \& Moore, T. J. (2019). The impact of integrated STEM professional development on teacher quality. School Science and Mathematics, 119(2), 105-114. https:/doi.org/10.1111/ssm.12318

El-Deghaidy, H., Mansour, N., Alzaghibi, M., \& Alhammad, K. (2017). Context of STEM integration in schools: views from in-service science teachers. Eurasia Journal of Mathematics Science \& Technology Education, 13(6), 2459-2484.

English, L. D. (2016). STEM education K-12: perspectives on integration. International Journal of STEM Education, 3(1), 3. https://doi.org/10.1186/s40594-016-0036-1

Estapa, A. T., \& Tank, K. M. (2017). Supporting integrated STEM in the elementary classroom: a professional development approach centered on an engineering design challenge. International Journal of STEM Education, 4, 116. https://doi.org/10.1186/s40594-017-0058-3

Fensham, P. J. (2015). Connoisseurs of science: a next goal for science education? In R. F. Gunstone, A. Jones, D. Corrigan \& J. Dillon (Eds.), The future in learning science: what's in it for the learner? (pp. 35-59). Springer.

Fensham, P. J. (2016). The future curriculum for school science: what can be learnt from the past? Research in Science Education, 46(2), 165-185.

Freeman, B. (2015). Federal and state STEM policies and programmes spanning Australian education, training, science and innovation. In B. Freeman, S. Marginson \& R. Tytler (Eds.), Science, Technology, Engineering and Mathematics (pp. 178-200). Routledge.

Friedrichsen, P., Driel, J. H. V., \& Abell, S. K. (2011). Taking a closer look at science teaching orientations. Science Education, 95(2), 358-376.

Gao, Y. (2013). Report on China's STEM system. Centre for the Study of Higher Education, University of Melbourne. https://acola.org/wp-content/uploads/2 018/12/Consultant-Report-China.pdf. Accessed 28 Dec 2019

Heck, D. J., Plumley, C. L., Stylianou, D. A., Smith, A. A., \& Moffett, G. (2019). Scaling up innovative learning in mathematics: exploring the effect of different professional development approaches on teacher knowledge, beliefs, and instructional practice. Educational Studies in Mathematics, 102, 319-342. https://doi.org/10.1007/s10649-019-09895-6

Hoachlander, G., \& Yanofsky, D. (2011). Making STEM real. Educational Leadership, 68(6), 60-65.

Hodson, D. (1992). In search of a meaningful relationship: an exploration of some issues relating to integration in science and science education. International Journal of Science Education, 14(5), 541-562.

Hofer, B. K. (2001). Personal epistemology research: implications for learning and teaching. Educational Psychology Review, 13(4), 353-383.

Hofer, M., \& Grandgenett, N. (2012). TPACK development in teacher education: a longitudinal study of preservice teachers in a secondary M.A.Ed. program. Journal of Research on Technology in Education, 45(1), 83-106. https://doi.org/10.1080/15391523.2012.10782598

Holmlund, T.D., Lesseig, K. \& Slavit, D. (2018). Making sense of "STEM education" in K-12 contexts. International Journal of STEM Education, 5(32). https://doi. org/10.1186/s40594-018-0127-2

Hoyle, R. H., \& Kenny, D. A. (1999). Statistical power and tests of mediation. In R. H. Hoyle (Ed.), Statistical strategies for small sample research. Sage.

Johnson, L., \& Brown, S. (2011). Challenge based learning: the report from the implementation project (pp. 1-36). The New Media Consortium.

Jones, M. G., \& Carter, G. (2007). Science teacher attitudes and beliefs. In S. K. Abell, K. Appleton \& D. L. Hanuscin (Eds.), Handbook of research on science education (pp. 1067-1104). Lawrence Erlbaum. 
Jones, M. G., \& Leagon, M. (2014). Science teacher attitudes and beliefs: reforming practice. In N. G. Lederman \& S. K. Abell (Eds.), Handbook of research on science education, Volume II (pp. 844-861). Routledge.

Kam, K., Chan, H., Yeh, Y., \& Hsu, Y. (2019). A framework for examining teachers practical knowledge for STEM teaching. In Y. S. Hsu \& Y. F. Yeh (Eds.), AsiaPacific STEM teaching practices: From theoretical frameworks to practices. https://doi.org/10.1007/978-981-15-0768-7

Kelley, T. R., \& Knowles, J. G. (2016). A conceptual framework for integrated STEM education. International Journal of STEM Education, 3(1), 11. https://doi.org/10 1186/s40594-016-0046-Z

Koehler, M., \& Mishra, P. (2009). What is technological pedagogical content knowledge (TPACK)? Contemporary Issues in Technology and Teacher Education, 9(1), 60-70

Koehler, M. J., \& Mishra, P. (2005). What happens when teachers design educational technology? The development of technological pedagogical content knowledge. Journal of Educational Computing Research, 32(2), 131-152.

Kurup, P. M., Li, X., Powell, G., \& Brown, M. (2019). Building future primary teachers' capacity in STEM: based on a platform of beliefs, understandings and intentions. International Journal of STEM Education, 6(1), 10. https://doi. org/10.1186/s40594-019-0164-5

Kwak, Y. (2001). Profile change in preservice science teacher's epistemological and ontological beliefs about constructivist learning: implications for science teaching and learning [Doctoral dissertation, The Ohio State University].

NGSS Lead States. (2013). Next generation Science standards: for states, by states. The National Academies Press.

Lederman, N. G. (1992). Students' and teachers' conceptions of the nature of science: A review of the research. Journal of Research in Science Teaching, 29(4), 331-359.

Luft, J. A., \& Roehrig, G. H. (2007). Capturing science teachers' epistemological beliefs: the development of the teacher beliefs interview. Electronic Journal of Science Education, 11(2).

Marginson, S., Tytler, R., Freeman, B., \& Roberts, K. (2013). STEM: country comparisons: International comparisons of science, technology, engineering and mathematics (STEM) education. Final report. Australian Council of Learned Academies. http://hdl.handle.net/10536/DRO/DU:30059041. Accessed 28 Dec 2019.

Margot, K. C., \& Kettler, T. (2019). Teachers' perception of STEM integration and education: a systematic literature review. International Journal of STEM Education, 6(1), 2. https://doi.org/10.1186/s40594-018-0151-2.

Marsh, H. W., \& Hau, K. T. (1999). Confirmatory factor analysis: Strategies for small sample sizes. Statistical Strategies for Small Sample Research, 1, 251-284.

McMullin, K., \& Reeve, E. (2014). Identifying perceptions that contribute to the development of successful project lead the way pre-engineering programs in Utah. Journal of Technology Education, 26(1), 22-46. https://doi.org/10. 21061/jte.v26i1.a.2

Moore, T. J., Stohlmann, M. S., Wang, H. H., Tank, K. M., Glancy, A. W., \& Roehrig, G. H. (2014). Implementation and integration of engineering in K-12 STEM education. In J. Strobel, M. E. Cardella, \& Ş. Purzer (Eds.), Engineering in precollege settings: Synthesizing research, policy, and practices (pp. 35-60). Purdue University Press.

Nadelson, L. S., Callahan, J., Pyke P., Hay, A., Dance, M., \& Pfiester, J. (2013). Teacher STEM perception and preparation: Inquiry-based STEM professional development for elementary teachers. The Journal of Educational Research, 106(2), 157-168. https://doi.org/10.1080/00220671.2012.667014

Nathan, M., \& Pearson, G. (2014, June 15-18). Integration in K-12 STEM education: status, prospects, and an agenda for research [paper presentation]. 2014 ASEE Annual Conference \& Exposition, Indianapolis, Indiana. https://peer.asee.org/2 0673

National Research Council. (2012). Education for life and work: developing transferable knowledge and skills in the $21^{\text {st }}$ century. National Academies Press.

National Research Council. (2013). Monitoring progress toward successful K-12 STEM education: a nation advancing?. National Academies Press.

Olafson, L., \& Schraw, G. (2006). Teachers' beliefs and practices within and across domains. International Journal of Educational Research, 45(1-2), 71-84.

Osborne, J., \& Dillon, J. (2008). Science education in Europe: Critical reflections (Vol. 13). The Nuffield Foundation.

Phillips, D. C. (1997). How, why, what, when, and where: perspectives on constructivism in psychology and education. Issues in Education, 3(2), 151-194.

Ryder, J. (2015). Being professional: accountability and authority in teachers' responses to science curriculum reform. Studies in Science Education, 51(1), 87-120. https://doi.org/10.1080/03057267.2014.1001629
Sandoval, W. A. (2005). Understanding students' practical epistemologies and their influence on learning through inquiry. Science Education, 89(4), 634-656

Schoepp, K.W. (2004). Technology integration barriers in a technology-rich environment: a CBAM perspective [Master's thesis, University of Calgary]. ProQuest. https://www.learntechlib.org/p/116334/

Schommer, M. (1994). Synthesizing epistemological belief research: tentative understandings and provocative confusions. Educational Psychology Review, 6(4), 293-319.

Schultz, P. W. (2001). The structure of environmental concern: concern for self, other people, and the biosphere. Journal of Environmental Psychology, 21(4), 327-339.

Schulz, R. M. (2009). Reforming science education: part I. The search for a philosophy of science education. Science \& Education, 18(3-4), 225-249.

Schumacker, R. E., \& Lomax, R. G. (2016). A beginner's guide to structural equation modeling, (4th ed., ). Routledge.

Seals, C., Mehta, S., Berzina-Pitcher, l., \& Graves-Wolf, L. (2017). Enhancing teacher efficacy for urban STEM teachers facing challenges to their teaching. Journal of Urban Learning, Teaching, and Research, 13, 135-146.

Shernoff, D. J., Sinha, S., Bressler, D. M., \& Ginsburg, L. (2017). Assessing teacher education and professional development needs for the implementation of integrated approaches to STEM education. International Journal of STEM Education, 4(1), 13. https://doi.org/10.1186/ s40594-017-0068-1

Shulman, L. (1987). Knowledge and teaching: foundations of the new reform. Harvard Educational Review, 57(1), 1-23.

Shulman, L. S. (1986). Those who understand: knowledge growth in teaching. Educational Researcher, 15(2), 4-14.

Storksdieck, M. (2016). Critical information literacy as core skill for lifelong STEM learning in the 21st century: reflections on the desirability and feasibility for widespread science media education. Cultural Studies Of Science Education, 11(1), 167-182.

Tabachnick, B. G., \& Fidell, L. S. (2001). Using multivariate statistics (4th ed.). Allyn \& Bacon.

Tanenbaum, C. (2016). STEM 2026: a vision for innovation in STEM education. US Department of Education.

Tao, Y. (2019). Kindergarten teachers' attitudes toward and confidence for integrated stem education. Journal for STEM Education Research, 2, 154-171. https://doi.org/10.1007/s41979-019-00017-8

Thomm, E., \& Bromme, R. (2012). "It should at least seem scientific!" Textual features of "scientificness" and their impact on lay assessments of online information. Science Education, 96(2), 187-211.

Wahono, B., \& Chang, C. Y. (2019a). Development and validation of a survey instrument (AKA) towards attitude, knowledge and application of STEM. Journal of Baltic Science Education, 18, 63-76.

Wahono, B., \& Chang, C. Y. (2019b). Assessing teacher's attitude, knowledge, and application (AKA) on STEM: an effort to foster the sustainable development of STEM education. Sustainability, 11(4), 950. https://doi.org/10.3390/ su11040950

Yang, X., Kaiser, G., König, J., \& Blömeke, S. (2020). Relationship between preservice mathematics teachers' knowledge, beliefs and instructional practices in China. ZDM Mathematics Education, 52, 281-294. https://doi.org/https:// doi.org/10.1007/s11858-020-01145-x

Yildirim, B. (2016). An analyses and meta-synthesis of research on STEM education. Journal of Education and Practice, 7(34), 23-33. https://doi.org/10. 1166/asl.2016.8111

\section{Publisher's Note}

Springer Nature remains neutral with regard to jurisdictional claims in published maps and institutional affiliations. 